Research Article

\title{
First and Second Law Evaluation of Multipass Flat-Plate Solar Air Collector and Optimization Using Preference Selection Index Method
}

\author{
Nguyen Thanh Luan' ${ }^{1}$ and Nguyen Minh Phu $\mathbb{i D}^{2}$ \\ ${ }^{1}$ Faculty of Mechanical Engineering, Ho Chi Minh City University of Technology (HCMUT), \\ VNU-HCM, Ho Chi Minh City, Vietnam \\ ${ }^{2}$ Faculty of Heat and Refrigeration Engineering, Industrial University of Ho Chi Minh City (IUH), Ho Chi Minh City, Vietnam
}

Correspondence should be addressed to Nguyen Minh Phu; nguyenminhphu@iuh.edu.vn

Received 10 January 2021; Revised 28 February 2021; Accepted 18 March 2021; Published 28 March 2021

Academic Editor: Francisco Beltran-Carbajal

Copyright (c) 2021 Nguyen Thanh Luan and Nguyen Minh Phu. This is an open access article distributed under the Creative Commons Attribution License, which permits unrestricted use, distribution, and reproduction in any medium, provided the original work is properly cited.

\begin{abstract}
In this paper, different flow configurations of multipass flat-plate air collectors are explored. Multiple passes are formed from glass cover, absorber plate, and back plate. Five types of air collectors were analysed and optimized with respect to maximum efficiencies and minimum cost. The analytical prediction of the heat exchanger, pressure loss, and efficiencies was presented. The effects of mass flow rate from 0.01 to $0.02 \mathrm{~kg} / \mathrm{s}$, air channel depth from 15 to $30 \mathrm{~mm}$, and collector length from 1.5 to $2.5 \mathrm{~m}$ on different configurations were examined and compared. The results of the parametric study show that the triple-pass type has the greatest efficiency, whereas the smallest efficiency is of the single-pass type. Among double-pass types, the type with two glass covers and natural convection heat transfer achieved the highest effective and exergy efficiencies due to a reduction in the top loss. Double-pass type with single glass cover is not recommended from both energy and exergy standpoints. As the collector length increases, the effective efficiency decreases, but the exergy efficiency increases. The exergy performance of the triple-pass type can reach up to $5 \%$ at the air flow rate of $0.005 \mathrm{~kg} / \mathrm{s}$. Finally, multiobjective optimization using the preference selection index method is conducted with three targets including effective efficiency, exergy efficiency, and number of plates. Optimal results show that the triple-pass type with the lowest air flow rate and the longest length is the best. The effective and exergy efficiencies for the best case were found to be about $52.1 \%$ and $4.7 \%$, respectively. However, this type with the highest flow rate and the shortest length is the worst.
\end{abstract}

\section{Introduction}

The national sustainable energy strategy always gives priority for developing renewable energy. Tropical countries like Vietnam promote solar energy conversion due to vast and stable radiation intensity during the year. The common types of solar thermal energy conversion are solar power, solar hot water, and solar hot air. The first two kinds have been developing stably and commercially for a long time, while the solar hot air has been researching. This continuous research is due to two major problems. Firstly, the thermal energy of hot air cannot be stored like hot water because the air specific heat and density are small compared to water. Secondly, the small thermal conductivity of the air results in a low convection heat transfer coefficient. However, the application of solar air heater (SAH) is widespread for space heating [1], regeneration of desiccant [2], and drying of agricultural products [3]. Facing the needs and limitations of SAH, research on improving SAH performance is always paid attention [4]. Heat transfer improvement between the absorber plate and the air in the collector can be mentioned as the insertion of vortex generators [5], inclined plates [6], or roughness ribs on the absorber surface [7] to diminish the viscous sublayer close to the surface and create mixing of the primary and secondary flows.

Another measure is the collector duct divided into multiple air passes to reduce heat loss at the top of SAH because of the high temperature of the absorber plate. 
Previously, Chandra et al. [8] established an analytical model and equivalent resistance method to calculate triplepass air collector. Predictions from the two approaches were compared with experimental data to indicate discrepancies. Choudhury et al. [9] theoretically solved triple-pass air collector with single and double glass covers. They reported that low air flow rate and short collector length were the cost-effective solutions. Forson et al. [10] studied the theory and indoor experiment of double-duct SAH in the natural convection mode of air. They concluded that the collector efficiency decreased with increasing collector area. Ramadan et al. [11] have inserted a packed bed in the first pass of a double-pass SAH to increase the heat transfer surface. They recommend an air flow rate of less than $0.05 \mathrm{~kg} / \mathrm{s}$ to achieve high efficiency. Sopian et al. [12] added porous media to the second pass of a double-pass SAH. This correction achieves collector efficiency up to $70 \%$ which is greater than the traditional single-pass SAH. Ramani et al. [13] expanded the study of double-pass SAH with the porous material configuration at the second pass. They claim that the collector efficiency is $25 \%$ higher than that of the double-pass SAH without porous and $35 \%$ higher than that of the single-pass $\mathrm{SAH}$. Correction of the absorber surface to enhance heat transfer has been a concern for the past decade. El-Sebaii et al. [14] used a v-corrugated absorber surface in a doubleduct SAH. They realized that the air temperature leaving the collector was $5 \%$ higher and the efficiency was $14 \%$ higher than the smooth absorber surface. A finned absorber plate in a double-pass SAH was proposed and examined by ElSebaii et al. [15]. They reported that the optimum air flow rate was $0.0125 \mathrm{~kg} / \mathrm{s}$ to achieve the maximum hydraulic thermal efficiency of $40 \%$. Ho et al. [16] studied the effect of air recirculation fraction to the second pass in a wire mesh SAH. They reported that the optimal fraction was 0.5 for flat-plate collectors and 1 for wire mesh packed collectors. Yeh [17] studied to divide the airflow between the absorber plate and the back plate into multiple passes. The results showed that when the number of passes increased, the thermal efficiency increased, but the pressure loss penalty was not significant.

Recently, besides evaluating the energy efficiency and cost of multipass air collectors, the exergy efficiency estimation of the collector has been noted to fulfill the requirements needed for a thermal device. The exergy analysis is to quantify the availability of solar radiation which can be converted into its work potential and irreversibility due to exergy destruction. Velmurugan and Kalaivanan [18-21] studied the energy and exergy of multipass collectors with different configurations including ribbed, finned, wire mesh absorber plates. They reported that a mixed type of wire mesh in the second pass and fin in the first pass provides the highest energy and exergy efficiencies. Raj et al. [22] evaluated the exergy performance of a SAH under outdoor conditions. They concluded that the exergy efficiency increased with day time and mass flow rate due to the higher extracted useful energy. Abo-Elfadl [23] proposed 4E (energy, exergy, economic, and environmental) model to comprehensively investigate a double-pass SAH. They pointed out that finned SAH is the most feasible one in terms of exergoeconomic point of view. Experimental studies on different modifications for multipass SAH have been performed to demonstrate their effectiveness [24-26]. In addition, with the development of numerical algorithms and computer processors, CFD (computational fluid dynamics) studies have been conducted to reduce the experimental time and costs [27-31]. More recently, Heydari et al. [32] proposed and numerically examined a novel helical airflow path around triangular channels. From the simulation results, the distributions of variables within the SAH such as velocity, pressure, and temperature are clarified to explain the mechanism of heat transfer enhancement and the potential for efficiency improvement. Multipass air collector applications for drying agricultural produce and integrating photovoltaic are also found in the literature [33-35].

Extensive review indicates that there is more variation in the multipass air collector to improve heat transfer such as wire mesh, porous, or fin. But in all, it is still based on a flat-plate collector with a certain number of passes. No previous works have been found to address the simultaneous comparison of multipass SAHs and multiobjective optimization to determine the most feasible collector. Therefore, this study focuses on evaluating the flat-plate collector with different number of glass covers, absorber plate, and back plate in order to examine all the possible passes of air. Energy, exergy, and optimization studies firmly confirm the pertinent type among the many configurations and major dimensions of air collectors through an analytical investigation coupled to an optimization method called multicriteria decision-making technique.

\section{Model Formulation and Validation}

Figure 1 shows the five types of flat-plate collectors that were investigated for energy, exergy, and optimization in this study. Type 1 consists of two glass covers, an absorber plate, and a back plate. The air travels from top to bottom via 3 passes. Type 2 consists of a glass cover, an absorber plate, and a back plate. Therefore, two passes can be created from these plates. Type 3 consists of two glass covers and one back plate where the air can travels through two passes. A four-plate configuration with two passes is seen in type 4 , in which the air between the two glass covers is naturally convected. Type 5 consists of two glass covers and one absorber plate with the air blowing through single pass in order to compare with the multipass types of 1 to 4 .

2.1. Thermohydraulic Modelling. The mathematical model is presented in this section with the following assumptions:

(i) Flow is steady, incompressible, and one-dimensional (1D). In practical applications, such as convective drying, an air velocity was verified to obtain drying conditions. Thus, the airflow is assumed to be steady. The air velocity inside the solar air heater duct is moderate so that air temperature is high enough to serve a certain duty. Therefore, the airflow is considered incompressible. Variation of air pressure and temperature is along with duct length leading to the 1D flow consideration. 


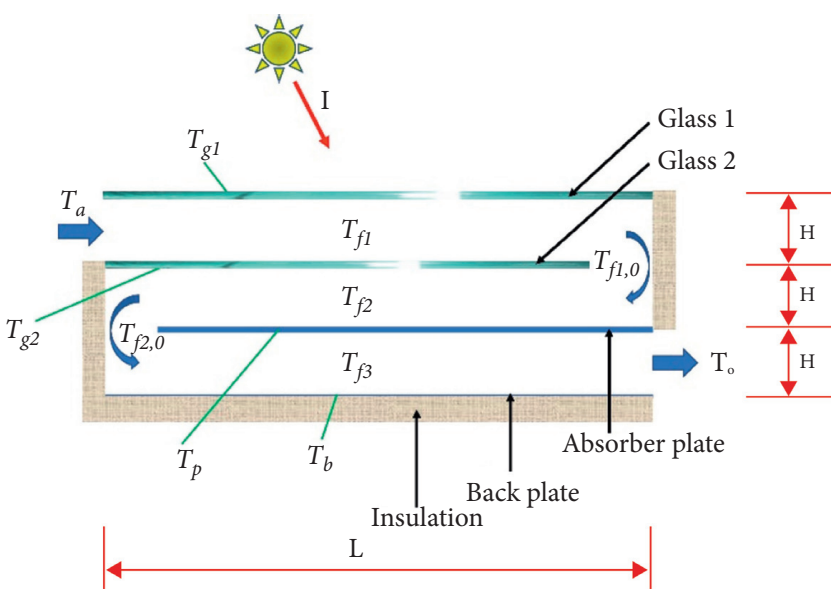

(a)

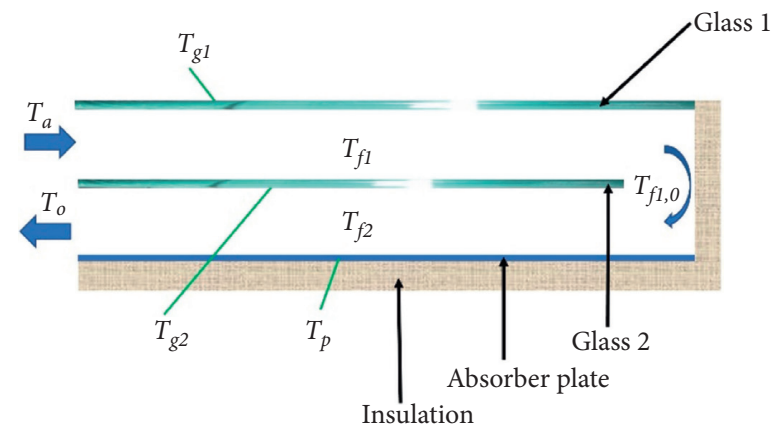

(c)

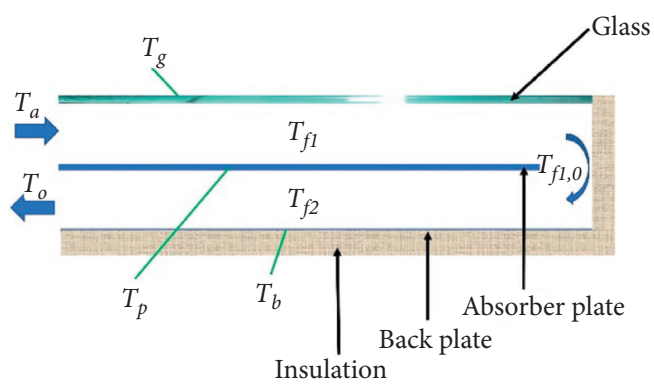

(b)

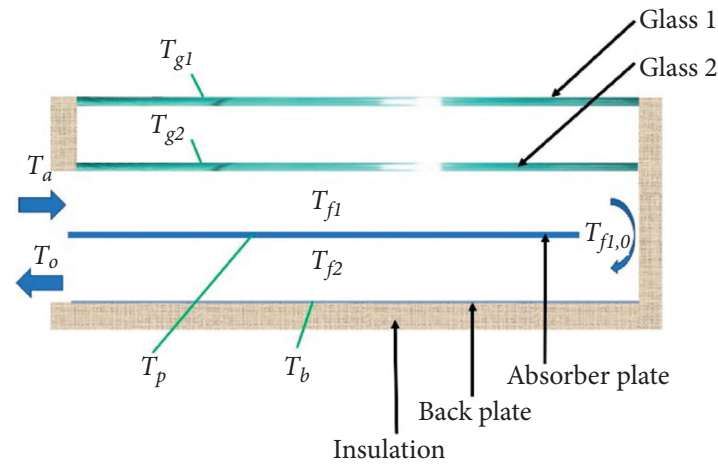

(d)

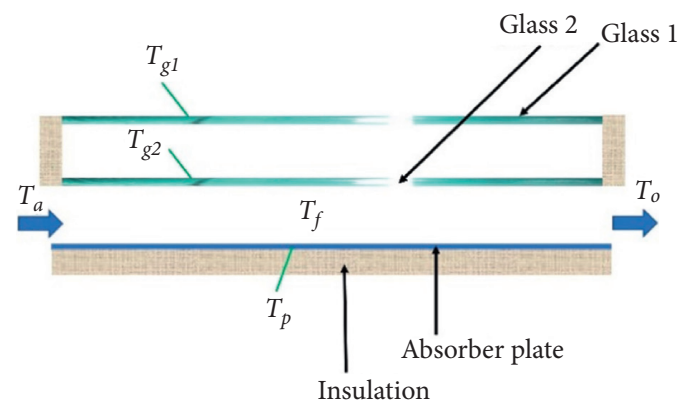

(e)

Figure 1: Configurations of solar air heater. (a) Type 1: triple-pass, double glass cover. (b) Type 2: double-pass, single glass cover. (c) Type 3: double-pass, double glass cover. (d) Type 4: double-pass, double glass cover. (e) Type 5: single-pass, double glass cover.

(ii) Thermal conduction in glass cover, absorber plate, and back plate is not considered due to their small thicknesses. The temperatures of these plates are homogeneous and equal to the average temperature. Multipoint temperature measurement on a plate is required in experiments, and the average temperature can be estimated by taking arithmetic mean [26].

(iii) The thermophysical properties of air, glass, and plates are constants because of low temperature change of a flat-plate air collector.

Equations (1)-(7) present the energy balance for type 1 as illustrated in Figure 2(a). Type 1 consists of 4 plates (2 glass covers, 1 absorber plate, and 1 back plate) and the fluid at 3 passes, so it takes seven equations to find seven corresponding temperatures. The thermal balance equation for the top glass cover is given below. The solar thermal energy absorption of the glass is equal to the amount of thermal energy released to the surrounding by convection and radiation, the heat transfer to the air in the first pass, and the heat transferred by radiation between the two glass covers [13]:

$$
\begin{aligned}
\alpha_{g} I= & h_{w}\left(T_{g 1}-T_{a}\right)+h_{r, g 1, s}\left(T_{g 1}-T_{s}\right) \\
& +h_{c, g 1, f 1}\left(T_{g 1}-T_{f 1}\right)+h_{r, g 1, g 2}\left(T_{g 1}-T_{g 2}\right) .
\end{aligned}
$$




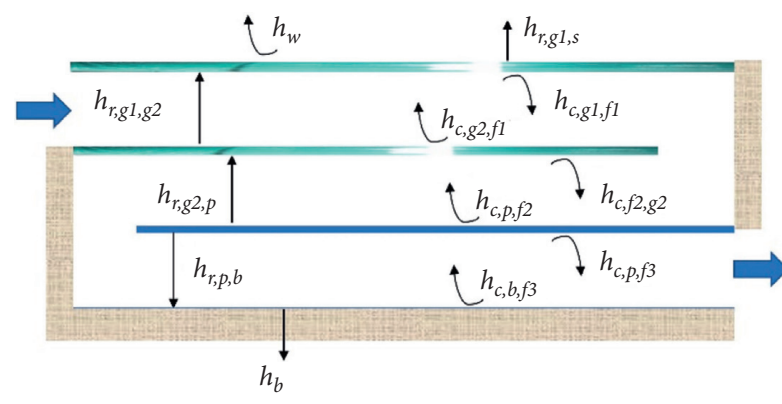

(a)

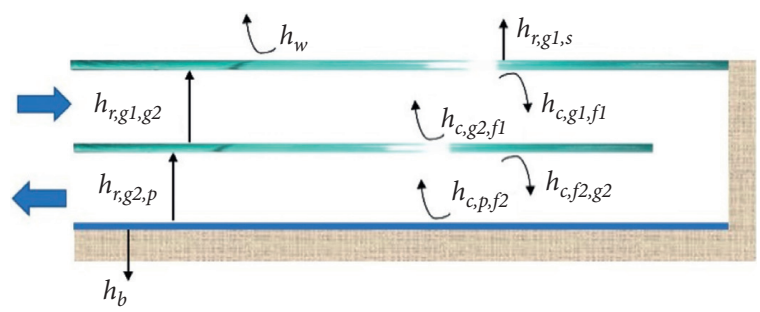

(c)

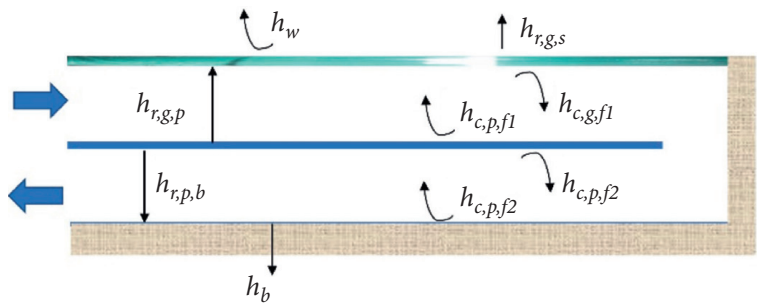

(b)

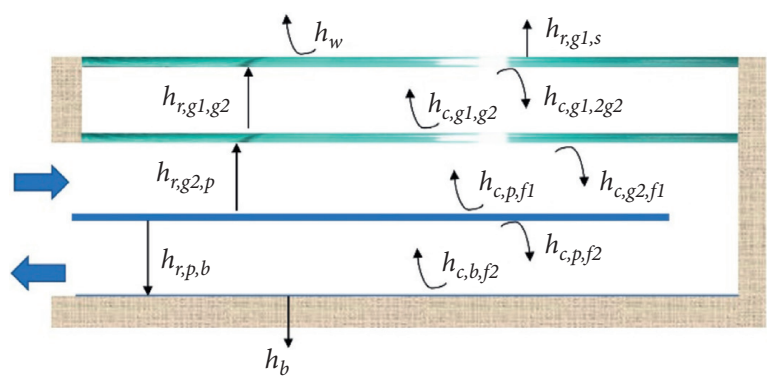

(d)

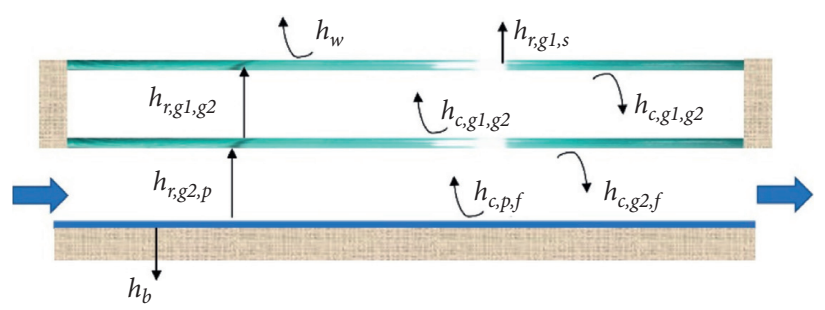

(e)

Figure 2: Energy balance diagram for plates and glass covers. (a) Type 1. (b) Type 2. (c) Type 3. (d) Type 4. (e) Type 5.

The air in the first pass receives heat from the two glass covers and increases its temperature. The temperature gradient can be approximated by the temperature difference between the inlet and outlet of the channel $[16,20]$ :

$$
\begin{aligned}
Q_{1}= & m c_{p}\left(T_{f 1, o}-T_{a}\right)=L b h_{c, g 1, f 1}\left(T_{g 1}-T_{f 1}\right) \\
& +L b h_{c, g 2, f 1}\left(T_{g 2}-T_{f 1}\right) .
\end{aligned}
$$

The lower glass cover absorbs solar radiation equaled to the convection heat transfer with the airflows at first and second passes, and the radiant heat exchanges with the upper glass cover and the absorber plate:

$$
\begin{aligned}
\alpha_{g} \tau_{g} I= & h_{c, g 2, f 1}\left(T_{g 2}-T_{f 1}\right)+h_{r, g 1, g 2}\left(T_{g 2}-T_{g 1}\right) \\
& +h_{c, f 2, g 2}\left(T_{g 2}-T_{f 2}\right)+h_{r, g 2, p}\left(T_{g 2}-T_{p}\right) .
\end{aligned}
$$

Thermal balance of fluid in the second pass is formed via convection heat transfer with the lower glass cover and absorber plate:

$$
\begin{aligned}
Q_{2}= & m c_{p}\left(T_{f 2, o}-T_{f 1, o}\right)=L b h_{c, f 2, g 2}\left(T_{g 2}-T_{f 2}\right) \\
& +L b h_{c, p, f 2}\left(T_{p}-T_{f 2}\right) .
\end{aligned}
$$

The heat gain from solar radiation of the absorber plate is balanced with the heat transferred to the fluid at the second and third passes and with the radiant heat transfer to the lower glass cover and back plate:

$$
\begin{aligned}
\alpha_{p} \tau_{g}^{2} I= & h_{c, p, f 2}\left(T_{p}-T_{f 2}\right)+h_{r, g 2, p}\left(T_{p}-T_{g 2}\right) \\
& +h_{c, p, f 3}\left(T_{p}-T_{f 3}\right)+h_{r, p, b}\left(T_{p}-T_{b}\right) .
\end{aligned}
$$

Thermal balance of fluid in the third pass is composed of convective heat transfer with absorber plate and back plate:

$$
\begin{aligned}
Q_{3}= & m c_{p}\left(T_{f 3, o}-T_{f 2, o}\right)=L b h_{c, p, f 3}\left(T_{p}-T_{f 3}\right) \\
& +L b h_{c, b, f 3}\left(T_{b}-T_{f 3}\right) .
\end{aligned}
$$

The back plate received thermal radiation from the absorber plate equilibrates with the convection heat exchange to the air in the third pass and the heat loss from the back plate to the environment:

$$
h_{r, p, b}\left(T_{p}-T_{b}\right)=h_{c, b, f 3}\left(T_{b}-T_{f 3}\right)+h_{b}\left(T_{b}-T_{a}\right) .
$$

In the above equations, the fluid temperature $\left(T_{f}\right)$ in a pass is taken as the average value of inlet and outlet 
temperatures of the pass. This is due to the fact that the convective heat transfer coefficient $\left(h_{c}\right)$ was developed based on the fluid bulk mean temperature.

$$
\begin{aligned}
& T_{f 1}=0.5\left(T_{a}+T_{f 1, o}\right), \\
& T_{f 2}=0.5\left(T_{f 2,0}+T_{f 1, o}\right), \\
& T_{f 3}=0.5\left(T_{o}+T_{f 2, o}\right) .
\end{aligned}
$$

Equations (1)-(7) are rearranged in matrix form as follows:

$$
\left[\begin{array}{ccccccc}
S_{11} & -h_{c, g 1, f 1} & -h_{r, g 1, g 2} & 0 & 0 & 0 & 0 \\
L b h_{c, g 1, f 1} & S_{22} & L b h_{c, g 2, f 1} & 0 & 0 & 0 & 0 \\
-h_{r, g 1, g 2} & -h_{c, g 2, f 1} & S_{33} & -h_{c, f 2, g 2} & -h_{r, g 2, p} & 0 & 0 \\
0 & 4 m c_{p} & L b h_{c, f 2, g 2} & S_{44} & L b h_{c, p, f 2} & 0 & 0 \\
0 & 0 & -h_{r, g 2, p} & -h_{c, p, f 2} & S_{55} & -h_{c, p, f 3} & -h_{r, p, b} \\
0 & 4 m c_{p} & 0 & -4 m c_{p} & -L b h_{c, p, f 3} & S_{66} & -L b h_{c, b, f 3} \\
0 & 0 & 0 & 0 & h_{r, p, b} & h_{c, b, f 3} & S_{77}
\end{array}\right]\left[\begin{array}{c}
T_{g 1} \\
T_{f 1} \\
T_{g 2} \\
T_{f 2} \\
T_{p} \\
T_{f 3} \\
T_{b}
\end{array}\right]=\left[\begin{array}{c}
S_{1} \\
S_{2} \\
S_{3} \\
S_{4} \\
S_{5} \\
S_{6} \\
S_{7}
\end{array}\right],
$$

where

$$
\begin{aligned}
S_{11} & =h_{w}+h_{r, g 1, s}+h_{c, g 1, g 2}+h_{r, g 1, g 2}, \\
S_{1} & =\alpha_{g} I+h_{w} T_{a}+h_{r, g 1, s} T_{s}, \\
S_{22} & =-\left(2 m c_{p}+L b h_{c, g 2, f 1}+L b h_{c, g 1, f 1}\right), \\
S_{2} & =-2 m c_{p} T_{a}, \\
S_{33} & =h_{c, g 2, f 1}+h_{r, g 1, g 2}+h_{c, g 2, f 2}+h_{r, g 2, p}, \\
S_{3} & =\alpha_{g} \tau_{g} I, \\
S_{44} & =-\left(2 m c_{p}+L b h_{c, f 2, g 2}+L b h_{c, p, f 2}\right), \\
S_{4} & =2 m c_{p} T_{a}, \\
S_{55} & =h_{c, p, f 2}+h_{r, g 2, p}+h_{c, p, f 3}+h_{r, p, b}, \\
S_{5} & =\alpha_{g} \tau_{g}^{2} I, \\
S_{66} & =2 m c_{p}+L b h_{c, p, f 3}+L b h_{c, b, f 3}, \\
S_{6} & =2 m c_{p} T_{a}, \\
S_{77} & =-\left(h_{r, p, b}+h_{c, b, f 3}+h_{b}\right), \\
S_{7} & =-h_{b} T_{a} .
\end{aligned}
$$

The appendix presents the system of equations for determining the temperatures of the remaining types associated with the energy balance diagram in Figures 2(b)-2(e). From equation (9), it is possible to solve seven temperatures once the convection heat transfer coefficients and radiant heat transfer coefficients are specified. The convection heat transfer coefficient of the top glass cover with the ambient air is calculated from McAdams' equation as follows [36]:

$$
h_{w}=5.7+3.8 V_{w} \text {. }
$$

The forced convective heat transfer coefficient of the air in the collector is predicted using the Dittus-Boelter formula as follows [37]:

$$
h_{c}=0.023 \operatorname{Re}^{0.8} \operatorname{Pr}^{0.4} \frac{k}{D_{h}} .
$$

The natural convection heat transfer coefficient between 2 glass covers of types 4 and 5 is estimated by [20]

$$
h_{c, g 1, g 2}=1.25\left(T_{g 2}-T_{g 1}\right)^{0.25} \text {. }
$$

The radiant heat transfer coefficient from the top glass cover to the sky is evaluated by the following correlation:

$$
h_{r, g, s}=\sigma \varepsilon_{g}\left(T_{g}^{2}+T_{s}^{2}\right)\left(T_{g}+T_{s}\right) .
$$

The sky temperature is calculated from the following equation [38]:

$$
T_{s}=0.0552 T_{a}^{1.5} .
$$

Generally, the radiant heat transfer coefficient between the two surfaces $s 1$ and $s 2$ is computed from their temperature and emissivity as follows [39]:

$$
h_{r, s 1, s 2}=\sigma\left(T_{s 1}^{2}+T_{s 2}^{2}\right) \frac{T_{s 1}+T_{s 2}}{\left(1 / \varepsilon_{s 1}\right)+\left(1 / \varepsilon_{s 1}\right)-1} .
$$

The conductive heat transfer coefficient from the back plate to surroundings is determined by

$$
h_{b}=\frac{k_{i}}{t_{i}} \text {. }
$$

The hydraulic diameter is defined as follows:

$$
D_{h}=\frac{4 H b}{2(H+b)} \text {. }
$$


The Reynolds number is given by

$$
\operatorname{Re}=\frac{2 m}{\mu(b+H)} \text {. }
$$

The thermal efficiency, i.e., first law efficiency, is the ratio of the heat gain received by air through $\mathrm{SAH}$ to the solar radiation coming from the absorption surface:

$$
\eta_{I}=\frac{Q}{L b I}
$$

where $Q$ is the useful heat gain received by the air: $Q=m c_{p}\left(T_{o}-T_{a}\right)$.

When reconfiguring a thermal device to improve its heat transfer, it is likely that pressure loss also increases. Therefore, it is necessary to evaluate hydraulic dissipated power. The pressure loss of the air through the collector is the sum of the pressure loss due to friction and the minor loss due to $180^{\circ}$ return bend between successive passes:

$$
\Delta P=\Delta P_{\text {smooth }}+\Delta P_{\text {bend }} .
$$

The frictional pressure loss is evaluated as

$$
\Delta P_{\text {smooth }}=n_{\text {pass }} \rho f V^{2} \frac{L}{D_{h}},
$$

where $f$ is the friction factor.

The friction factor can be calculated by [11]

$$
f=0.059 \operatorname{Re}^{-0.2} \text {. }
$$

Minor pressure loss by $180^{\circ}$ return bend can be estimated as

$$
\Delta P_{\text {bend }}=\left(n_{\text {pass }}-1\right) K_{\text {bend }} \rho \frac{V^{2}}{2}
$$

where $K_{\text {bend }}$ is minor loss coefficient for $180^{\circ}$ return bend, $K_{\text {bend }}=2.2$ [19].

The energy required to transport fluid against pressure loss is calculated as follows:

$$
P_{\text {flow }}=m \frac{\Delta P}{\rho} \text {. }
$$

The difference between the useful heat gain and pumping power is attributed to effective efficiency as

$$
\eta_{\text {eff }}=\frac{Q-\left(P_{\text {flow }} / C_{o}\right)}{L b I} .
$$

where $C_{o}$ is the conversion factor considering the thermal energy equivalent of blower power, $C_{o}=0.2$ [38].

2.2. Exergy-Based Modelling. The input exergy of the SAH is constituted by the air inflow and solar radiation source as follows $[5,38]$ :

$$
\sum E X_{\text {inlet }}=I A_{c}\left[1-\left(\frac{4}{3}\right)\left(\frac{T_{a}}{T_{\text {sun }}}\right)+\left(\frac{1}{3}\right)\left(\frac{T_{a}}{T_{\text {sun }}}\right)^{4}\right],
$$

where $T_{\text {sun }}$ is the sun temperature, $T_{\text {sun }}=4350 \mathrm{~K} \mathrm{[38],} \mathrm{and}$ $A_{c}=L_{b}$ is the absorber plate area.

The exergy losses of a solar air heater have been derived into five components including optical loss, the loss due to heat transfer from the absorber plate to the environment, the loss due to solar radiation absorption of the absorber plate, the loss due to heat transfer from the absorber plate to the air, and the frictional loss of the air flowing in SAH. These qualities are quantified as follows:

(1) Optical exergy losses:

$$
\mathrm{EX}_{\text {loss }, \mathrm{opt}}=I A_{c}\left(1-\tau^{n_{g}} \alpha\right)\left[1-\left(\frac{4}{3}\right)\left(\frac{T_{a}}{T_{\text {sun }}}\right)+\left(\frac{1}{3}\right)\left(\frac{T_{a}}{T_{\text {sun }}}\right)^{4}\right]
$$

(2) Exergy losses by convection and radiation heat transfer from the absorber plate to the environment:

$$
\mathrm{EX}_{\mathrm{loss}, \mathrm{Q}_{\mathrm{loss}}}=U_{L} A_{c}\left(T_{p}-T_{a}\right)\left(1-\frac{T_{a}}{T_{p}}\right)
$$

where $U_{L}$ is the total loss coefficient:

$$
U_{L}=U_{t}+h_{b} \text {. }
$$

The heat loss from the top of each $\mathrm{SAH}$ is calculated by convection and radiation heat transfer coefficients above absorber plate as [38]

$$
\begin{aligned}
& U_{t}=\left(\frac{1}{h_{w}+h_{r, g 1, s}}+\frac{1}{h_{c, g 2, f 1}+h_{r, g 1, g 2}}+\frac{1}{h_{c, p, f 2}+h_{r, g 2, p}}\right)^{-1}, \text { for type I and III, } \\
& U_{t}=\left(\frac{1}{h_{w}+h_{r, g, s}}+\frac{1}{h_{c, p, f 1}+h_{r, g, p}}\right)^{-1}, \text { for type II, } \\
& U_{t}=\left(\frac{1}{h_{w}+h_{r, g 1, s}}+\frac{1}{h_{c, g 1, g 2}+h_{r, g 1, g 2}}+\frac{1}{h_{c, p, f 1}+h_{r, g 2, p}}\right)^{-1}, \text { for type IV, }
\end{aligned}
$$




$$
U_{t}=\left(\frac{1}{h_{w}+h_{r, g 1, s}}+\frac{1}{h_{c, g 1, g 2}+h_{r, g 1, g 2}}+\frac{1}{h_{c, p, f}+h_{r, g 2, p}}\right)^{-1}, \text { for type V. }
$$

(3) Exergy losses by absorption of radiation by the absorber plate:

$$
\mathrm{EX}_{\mathrm{loss}, T_{p}, T_{\text {sun }}}=I A_{c} \tau^{n_{g}} \alpha\left[1-\left(\frac{4}{3}\right)\left(\frac{T_{a}}{T_{\text {sun }}}\right)+\left(\frac{1}{3}\right)\left(\frac{T_{a}}{T_{\text {sun }}}\right)^{4}-\left(1-\frac{T_{a}}{T_{p}}\right)\right]
$$

where $n_{\mathrm{g}}$ is the number of glass covers.

(4) Exergy losses by heat transfer to the working air:

$$
\mathrm{EX}_{\text {loss }, T_{p}, T_{f}}=I A_{c} \eta_{I} T_{a}\left(\frac{1}{T_{f}}-\frac{1}{T_{p}}\right)
$$

where $T_{f}$ is the mean temperature of the working air, $T_{f}=0.5\left(T_{a}+T_{o}\right)$.

(5) Frictional exergy losses of the working air:

$$
\mathrm{EX}_{\text {loss,friction }}=\frac{m \Delta p T_{a}}{\rho T_{f}}
$$

The first two kinds of exergy losses are external losses. The remaining kinds are known as internal losses. The total exergy losses are determined by summing the abovementioned exergy losses:

$$
\begin{aligned}
\sum \mathrm{EX}_{\text {loss }}= & \mathrm{EX}_{\text {loss }, \mathrm{opt}}+\mathrm{EX}_{\mathrm{loss}, \mathrm{Q}_{\mathrm{loss}}}+\mathrm{EX}_{\mathrm{loss}, T_{p}, T_{\mathrm{sun}}} \\
& +\mathrm{EX}_{\mathrm{loss}, T_{p}, T_{f}}+\mathrm{EX}_{\text {loss,friction. }}
\end{aligned}
$$

The exergy efficiency can be calculated by summing the total exergy losses and input exergy as follows:

$$
\eta_{\mathrm{II}}=1-\frac{\sum E X_{\text {loss }}}{\sum E X_{\text {inlet }}}
$$

\subsection{Preference Selection Index Method for Multiobjective} Optimization. Choosing a final solution may involve multiobjective optimization. In this study, three objective functions were selected including maximum effective efficiency, maximum exergy yield, and minimum total number of plates. The total number of plates is composed of glass covers, absorber plate, and back plate. This is a parameter related to the capital cost of a multiple pass air collector so it should be minimal. There are many multiobjective optimization methods. The preference selection index (PSI) method is chosen in the current work due to its explicit approach, simplicity, and no need to choose weights $[40,41]$. The method is the objective approach oriented to multicriteria decision-making which was recently devised by Mania and Bhatt [42]. Nowadays, the PSI method is widely applied in many fields [43].
The performance procedure of the PSI method can be summarised as follows [40, 41]:

Step 1: normalization of criteria

For criteria needed to be maximized, i.e., $\eta_{\mathrm{eff}}$ and $\eta_{\mathrm{II}}$ :

$$
\begin{aligned}
& d_{i, \eta_{\mathrm{eff}}}=\frac{\eta_{\mathrm{eff}}^{i}}{\eta_{\mathrm{eff}}^{\mathrm{max}}}, \\
& d_{i, \eta_{\mathrm{II}}}=\frac{\eta_{\mathrm{II}}^{i}}{\eta_{\mathrm{II}}} .
\end{aligned}
$$

For criterion needed to be minimized, i.e., total number of glass cover, absorber plate, and back plate:

$$
d_{i, N_{\text {plate }}}=\frac{N_{\text {plate }}^{\min }}{N_{\text {plate }}^{i}}
$$

(i) where $i$ is $i^{\text {th }}$ case, there are 135 cases in the current study, and therefore, $i=1$ to 135 .

Step 2: find the mean value of an objective

$$
\begin{gathered}
\Delta_{\eta_{\text {eff }}}=\frac{1}{135} \sum_{i=1}^{135} d_{i, \eta_{\text {eff }},} \\
\Delta_{\eta_{\text {II }}}=\frac{1}{135} \sum_{i=1}^{135} d_{i, \eta_{\text {II }}}, \\
\Delta_{N_{\text {plate }}}=\frac{1}{135} \sum_{i=1}^{135} d_{i, N_{\text {plate }}} .
\end{gathered}
$$

Step 3: compute the preference variation value

$$
\begin{aligned}
\chi_{\eta_{\text {eff }}} & =\sum_{i=1}^{135}\left(d_{i, \eta_{\text {eff }}}-\Delta_{\eta_{\text {eff }}}\right)^{2}, \\
\chi_{\eta_{\text {II }}} & =\sum_{i=1}^{135}\left(d_{i, \eta_{\text {II }}}-\Delta_{\eta_{\mathrm{II}}}\right)^{2}, \\
\chi_{N_{\text {plate }}} & =\sum_{i=1}^{135}\left(d_{i, N_{\text {plate }}}-\Delta_{N_{\text {plate }}}\right)^{2} .
\end{aligned}
$$


Step 4: evaluate deviation of preference variation value

$$
\begin{gathered}
\theta_{\eta_{\text {eff }}}=1-\frac{\chi_{\eta_{\text {eff }}}}{135-1}, \\
\theta_{\eta_{\text {II }}}=1-\frac{\chi_{\eta_{\text {II }}}}{135-1}, \\
\theta_{N_{\text {plate }}}=1-\frac{\chi_{N_{\text {plate }}}}{135-1} .
\end{gathered}
$$

Step 5: estimate the overall preference value

$$
\begin{gathered}
\varepsilon_{\eta_{\text {eff }}}=\frac{\theta_{\eta_{\text {eff }}}}{\theta_{\eta_{\text {eff }}+\theta_{\eta_{\text {II }}}+\theta_{N_{\text {plate }}}}} \\
\varepsilon_{\eta_{\text {II }}}=\frac{\theta_{\eta_{\text {II }}}}{\theta_{\eta_{\text {eff }}}+\theta_{\eta_{\text {II }}}+\theta_{N_{\text {plate }}}}, \\
\varepsilon_{N_{\text {plate }}}=\frac{\theta_{N_{\text {plate }}}}{\theta_{\eta_{\text {eff }}}+\theta_{\eta_{\text {II }}}+\theta_{N_{\text {plate }}}} .
\end{gathered}
$$

Step 6: calculate the preference selection index value for each case

$$
\Omega_{i}=d_{i, \eta_{\text {eff }}} \varepsilon_{\eta_{\text {eff }}}+d_{i, \eta_{\text {II }}} \varepsilon_{\eta_{\text {II }}}+d_{i, N_{\text {plate }}} \varepsilon_{N_{\text {plate }}} .
$$

Table 1 displays the input parameters entered into the mathematical model for all of the collector types examined. The above system of mathematical equations is solved in the Engineering Equation Solver (F-chart software) which specializes in solving system of nonlinear equations. Figure 3 shows the comparison of the calculated results from the current study with the published experimental results for collector types 4 and 5. It can be stated that the results in this study are slightly overestimated compared to the experimental results. This is because the predictions are limited as the above assumptions compared with the practical applications. However, analytical predictions coincide well with the experimental approaches. Verifications have been performed about heat transfer and hydraulics of single-pass and multipass SAHs. Confirmation on the prediction of the exergy analysis model was presented in our previous study [5]. It is not repeated here for the sake of brevity. Hence, the mathematical modelling was extended to the remaining types and carried out further evaluation for all collectors.

\section{Results and Discussion}

This section presents the effects of air mass flow rate $(m)$, channel height $(H)$, and collector length $(L)$ on the energy and exergy performance of the types under consideration. Figures 4 and 5 consider the effect of mass flow rate while the collector geometry parameters are fixed. It can be observed in Figure 4 that the effective efficiency increases with the mass flow rate. As the flow rate increases, the intensity of the heat exchange increases, thus enhancing the useful heat gain of the air received from glass cover and plates. However, the flow rate increases as a result of rising the pressure loss. But the pressure loss penalty is negligible due to air moving in the smooth channels. At high flow rates, the efficiency increases slightly because of remarkable pressure loss. It can be seen that type 1 (triple-pass SAH) has the highest performance and type 5 (single-pass SAH) has the lowest performance. This verifies that a multipass air collector reduces top loss and higher temperature rise of air because the air receives thermal energy from four plates (two glass covers, one absorber plate, and one back plate). The double-pass types have fairly close efficiencies in which type 4 reveals better performance because this type owns two glass covers in natural convection heat transfer, thus significantly reducing top loss. At a small flow rate, the triple-pass SAH (type 1) is nearly twice as efficient as the single-pass $\mathrm{SAH}$ (type 5). However, at a large flow rate, the effective efficiency of type 1 is only $20 \%$ higher than that of type 5 due to the long travel of the air inside the triple-pass SAH.

Figure 5 shows at low flow (less than $0.02 \mathrm{~kg} / \mathrm{s}$ ) the triple-pass collector earns the greatest exergy performance followed by double-pass and single-pass collectors. This is because the exergy loss decreases with the increase in the pass number. At low flow, a collector with a large pass number has a high exergy performance due to the higher temperature of the fluid and lower temperature of absorber plate reducing exergy losses. Among the double-pass types (types 2, 3, and 4), the single glass cover SAH (type 2) has the smallest exergy performance due to the highest exergy loss from the absorber plate to the environment. Exergy performance obtained the maximum value at a certain flow rate due to trade-off of increase in frictional exergy loss and a decrease in exergy loss by heat transfer from the absorber plate to the environment with mass flow rate. At high mass flow rates, the exergy performances of the double-pass SAHs seem to be identical. This means that the absorber plate temperature of the double-pass SAHs is almost the same leading to alike exergy losses at those flow rates.

Figures 6 and 7 show the energy and exergy performance of multipass SAH with collector length $(L)$ at fixed air flow rate and channel height. It can be seen that the effective efficiency of air collectors decreases with increasing collector length. This is supposed due to the fact that the outlet air temperature does not increase linearly with the length. The fluid absorbs heat and increases its temperature along the flow path so that the longer length results in the lower temperature difference between the hot surface and the fluid. The small temperature difference causes an increase in useful heat gain by less than the order unity of the heat transfer length. At the same length, the effective efficiency increases with increasing the number of passes. For all double-pass types, type 4 is the best and type 2 is the worst as noted above. The triple-pass type has the largest slope because of the highest pressure loss. Contrary to the effective efficiency, the exergy efficiency increases with the collector length as can be seen in Figure 7. This is owing to the fact that the exergy loss due to heat transfer from the absorber plate to the fluid decreases because of the small temperature difference between the absorber plate and the airflow. Triple-pass $\mathrm{SAH}$ can achieve exergy performance of up to $5 \%$. This is a very 
TABLE 1: Input parameters.

\begin{tabular}{lccc}
\hline Parameter & Symbol & Value & Unit \\
\hline Solar radiation & $I$ & 1000 & 0.06 \\
Absorptivity of glass cover & $\alpha_{g}$ & 0.95 & $\mathrm{~W} / \mathrm{m}^{2}$ \\
Absorptivity of absorber plate & $a_{p}$ & 306 & $\mathrm{~K} \mathrm{~m} / \mathrm{s}$ \\
Ambient temperature & $T_{a}$ & 0.9 & \\
Wind velocity & $V_{w}$ & 0.84 \\
Emissivity of glass cover & $\varepsilon_{g}$ & 0.94 \\
Transmissivity of glass cover & $\tau_{g}$ & 0.94 \\
Emissivity of absorber plate & $\varepsilon_{p}$ & 15 to 30 \\
Emissivity of back plate & $\varepsilon_{b}$ & 1.5 to 2.5 \\
Channel depth & $H$ & 0.01 to 0.02 & 0.05 \\
Collector length & $L$ & 0.025 \\
Air mass flow rate & $m$ & 0.46 \\
Insulation thickness & $t_{i}$ & $\mathrm{~mm}$ \\
Thermal conductivity of insulation & $k_{i}$ & $\mathrm{~kg} / \mathrm{s}$ \\
Collector width & $b$ & $\mathrm{~m}$ \\
\hline
\end{tabular}

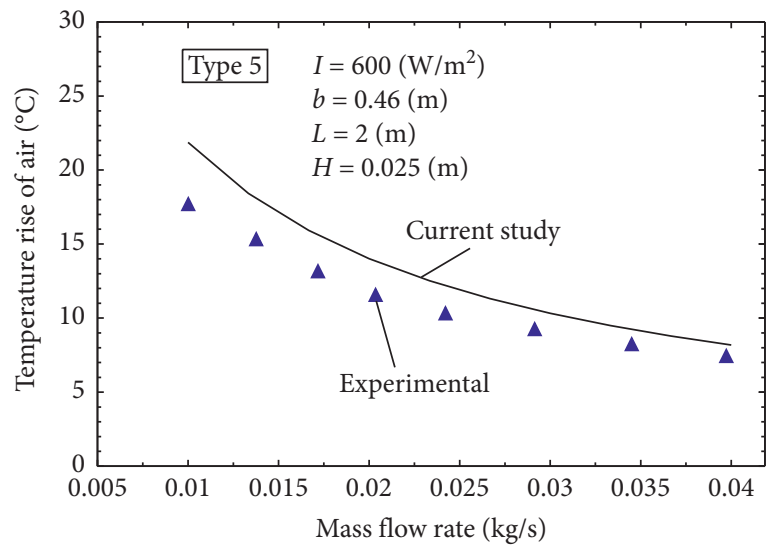

(a)

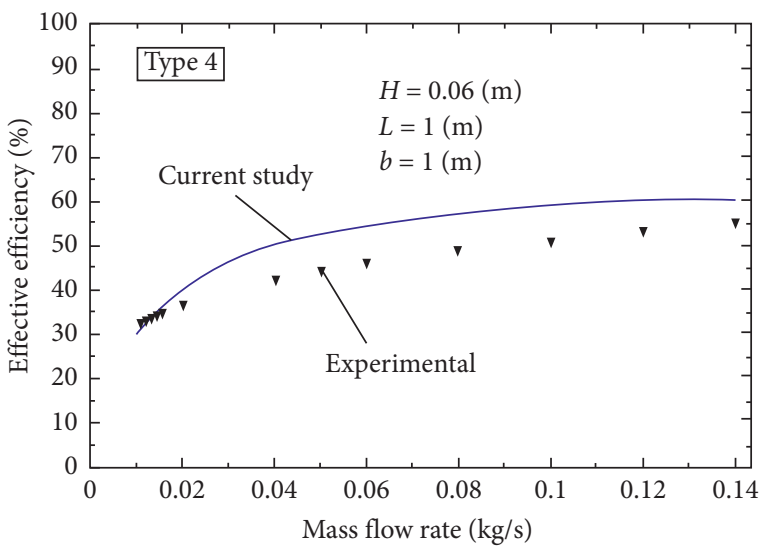

(b)

FIgURE 3: Verification of the current analytical results with experiments. (a) Comparison with experimental results [20] on type 5. (b) Comparison with experimental results [11] on type 4 .

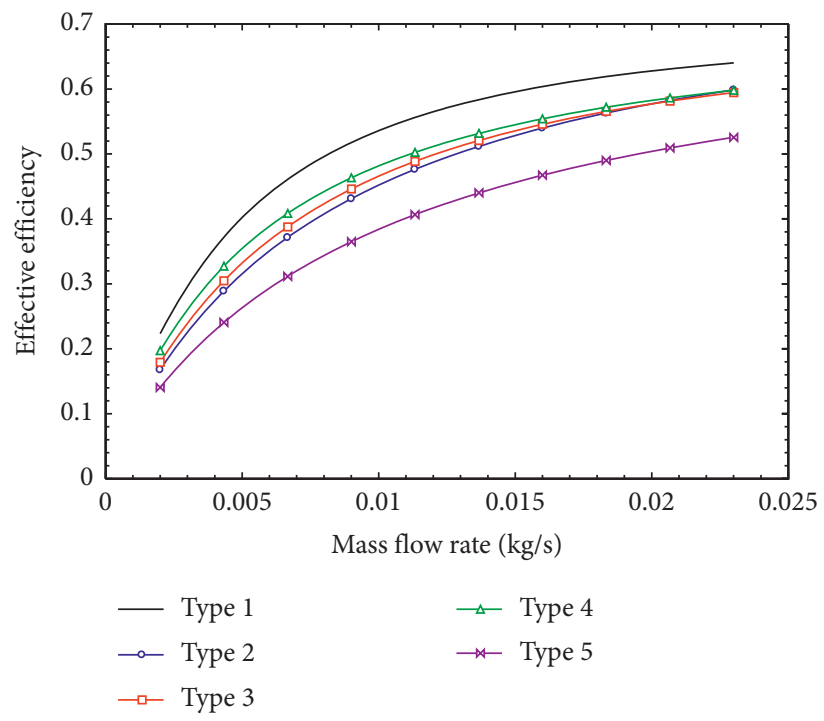

FIGURE 4: Effects of mass flow rate on effective efficiency. 


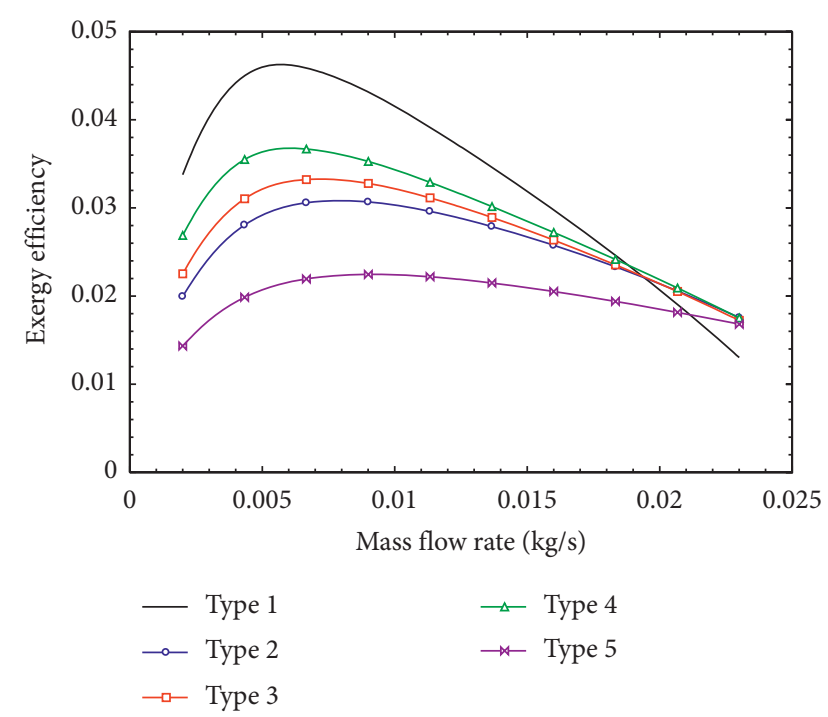

Figure 5: Effects of mass flow rate on exergy efficiency.

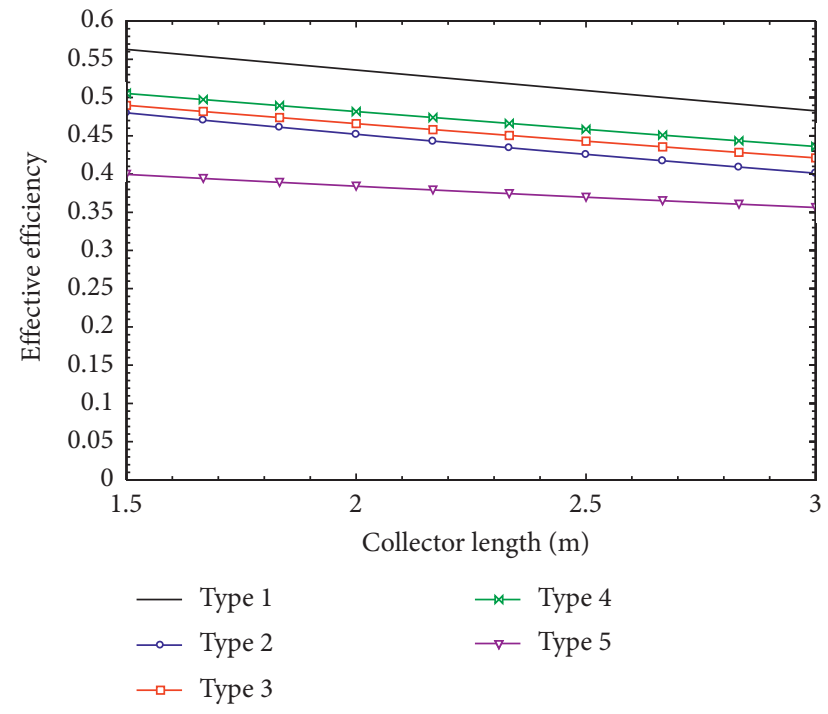

Figure 6: Effects of collector length on effective efficiency.

encouraging performance for a solar air heater. As it is known, SAH's exergy efficiency is very low, say $2 \%$, due to the great exergy destruction of converting solar radiation into heat [7].

The effect of channel depth $(H)$ on effective and exergy efficiencies is shown in Figures 8 and 9 with fixed air flow rate and collector length. Increasing the channel depth reduces the velocity of air blowing through hot surfaces leading to low convection heat transfer coefficient. Also, the low air velocity increases the surface temperatures resulting in increased heat losses such as top loss and the loss from back plate to the environment. Increasing the temperature of the plates with the depth increases the exergy losses due to heat transfer to the fluid and heat loss. Hence, the exergy performance decreases with the increase in the air channel

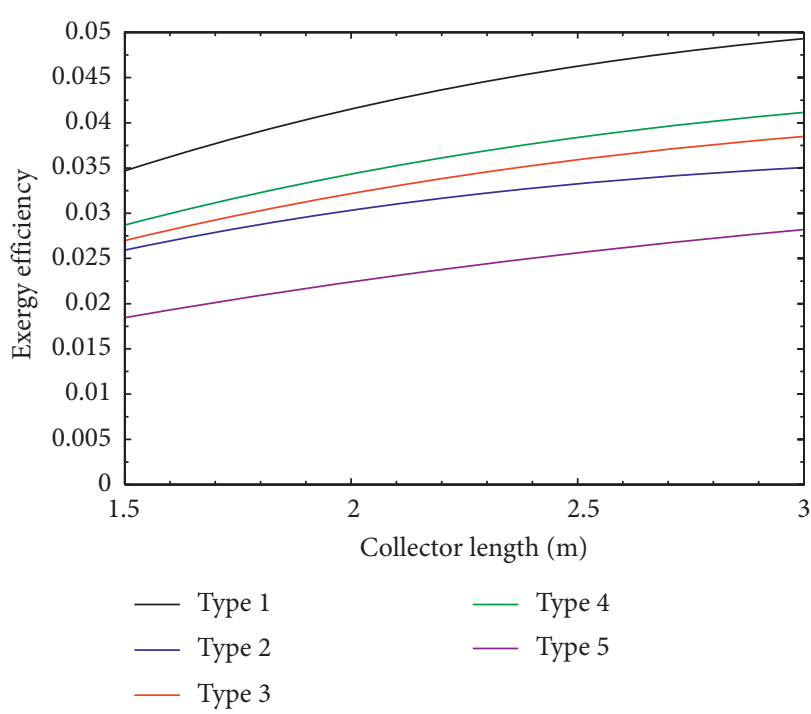

FiguRE 7: Effects of collector length on exergy efficiency.

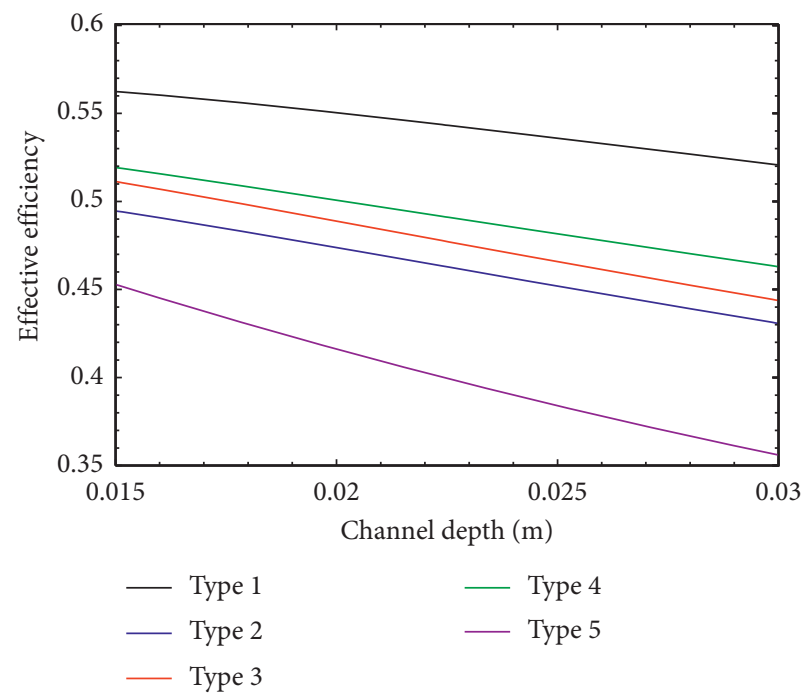

Figure 8: Effects of channel depth on effective efficiency.

depth as shown in Figure 9. However, it is worth noting that the exergy efficiency of the triple-pass SAH (type 1) reaches an extreme at the depth of $19 \mathrm{~mm}$. This can be explained by the fact that at a depth of less than $19 \mathrm{~mm}$, the fluid passing in the 3 passes reduces the temperature of the plates and the smallest top loss compared to other types. Thus, the exergy performance of the triple-pass type increases with the air channel depth from $15 \mathrm{~mm}$ to $19 \mathrm{~mm}$.

The analysis above showed the influence of the design, operation parameters, and collector type on the performance. The characteristics of each collector and the maximum efficiencies have been indicated. To initialize the optimization for searching the final solution, in this study, there are 5 types of collector and 3 design and operation parameters including mass flow rate (range $m=0.01-0.02 \mathrm{~kg} / \mathrm{s}$ ), collector length 


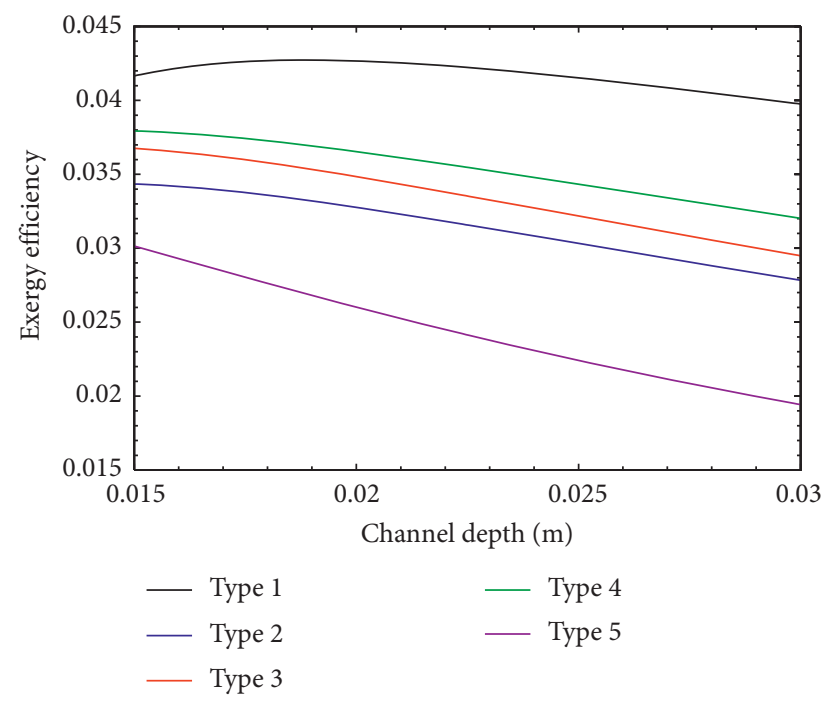

FIGURE 9: Effects of channel depth on exergy efficiency.

Table 2: Typical cases to be optimized using the PSI method.

\begin{tabular}{|c|c|c|c|c|c|c|c|}
\hline \multirow{2}{*}{ Case, $i$} & \multicolumn{4}{|c|}{ Design parameters } & \multicolumn{3}{|c|}{ Objectives } \\
\hline & Type & $m, \mathrm{~kg} / \mathrm{s}$ & $L, \mathrm{~m}$ & $H, \mathrm{~m}$ & $\eta_{\mathrm{eff}}$ & $N_{\text {plate }}$ & $\eta_{\mathrm{II}}$ \\
\hline 1 & 1 & 0.01 & 1.5 & 0.02 & 0.5796 & 4 & 0.03562 \\
\hline 2 & 1 & 0.01 & 1.5 & 0.025 & 0.5627 & 4 & 0.03469 \\
\hline 3 & 1 & 0.01 & 1.5 & 0.03 & 0.5456 & 4 & 0.03316 \\
\hline 4 & 1 & 0.01 & 2 & 0.02 & 0.5504 & 4 & 0.04266 \\
\hline 5 & 1 & 0.01 & 2 & 0.025 & 0.5359 & 4 & 0.04152 \\
\hline 6 & 1 & 0.01 & 2 & 0.03 & 0.5207 & 4 & 0.03975 \\
\hline 7 & 1 & 0.01 & 2.5 & 0.02 & 0.5209 & 4 & 0.04733 \\
\hline 8 & 1 & 0.01 & 2.5 & 0.025 & 0.509 & 4 & 0.04626 \\
\hline 9 & 1 & 0.01 & 2.5 & 0.03 & 0.496 & 4 & 0.04446 \\
\hline 10 & 1 & 0.015 & 1.5 & 0.02 & 0.6276 & 4 & 0.02198 \\
\hline 11 & 1 & 0.015 & 1.5 & 0.025 & 0.6151 & 4 & 0.02459 \\
\hline 12 & 1 & 0.015 & 1.5 & 0.03 & 0.6017 & 4 & 0.02516 \\
\hline 13 & 1 & 0.015 & 2 & 0.02 & 0.607 & 4 & 0.0297 \\
\hline 14 & 1 & 0.015 & 2 & 0.025 & 0.5958 & 4 & 0.03188 \\
\hline 15 & 1 & 0.015 & 2 & 0.03 & 0.5835 & 4 & 0.03209 \\
\hline 16 & 1 & 0.015 & 2.5 & 0.02 & 0.5854 & 4 & 0.03564 \\
\hline 17 & 1 & 0.015 & 2.5 & 0.025 & 0.5759 & 4 & 0.03763 \\
\hline 18 & 1 & 0.015 & 2.5 & 0.03 & 0.5648 & 4 & 0.03765 \\
\hline 19 & 1 & 0.02 & 1.5 & 0.02 & 0.6513 & 4 & 0.005287 \\
\hline 20 & 1 & 0.02 & 1.5 & 0.025 & 0.6424 & 4 & 0.01326 \\
\hline 21 & 1 & 0.02 & 1.5 & 0.03 & 0.6321 & 4 & 0.01661 \\
\hline 22 & 1 & 0.02 & 2 & 0.02 & 0.6359 & 4 & 0.01349 \\
\hline 23 & 1 & 0.02 & 2 & 0.025 & 0.6278 & 4 & 0.02069 \\
\hline 24 & 1 & 0.02 & 2 & 0.03 & 0.6181 & 4 & 0.02352 \\
\hline 25 & 1 & 0.02 & 2.5 & 0.02 & 0.6195 & 4 & 0.01999 \\
\hline 26 & 1 & 0.02 & 2.5 & 0.025 & 0.6125 & 4 & 0.02675 \\
\hline 27 & 1 & 0.02 & 2.5 & 0.03 & 0.6036 & 4 & 0.02927 \\
\hline
\end{tabular}

$(L=1.5-2.5 \mathrm{~m})$, and air channel height $(H=20-30 \mathrm{~mm})$ each at three levels. Hence, there are 135 cases in total which need to select the best one. Typically, Table 2 presents 27 cases for type 1 with inputs and outputs.

Table 3 shows the calculated values from steps $3-5$ of the PSI method for the objective functions under consideration. Table 4 exhibits selective 10 cases including 5 best cases (the highest preference selection indices) and 5 worst cases (the smallest preference selection indices). It is confirmed that type 1 with lowest flow rate, maximum collector length, and moderate channel depth reaches the final optimal solution. This is also consistent with the statement in the above parametric study. Otherwise, type 1 with the largest airflow is the worst case. In addition, single-pass SAH (type 5) is also 
TABLE 3: Values of $\chi, \theta$, and $\varepsilon$ of objective functions.

\begin{tabular}{lccc}
\hline Objectives & Preference variation value $\chi$ & Deviation of preference variation value $\theta$ & Overall preference value $\varepsilon$ \\
\hline Effective efficiency $\eta_{\mathrm{Eff}}$ & 1.435 & 0.9893 & 0.3356 \\
Exergy efficiency $\eta_{\mathrm{II}}$ & 2.025 & 0.9849 & 0.3341 \\
Number of plates $N_{\text {plate }}$ & 3.582 & 0.9733 & 0.3302 \\
\hline
\end{tabular}

TABLE 4: Results of preference selection index $\Omega$ and ranking for 5 best cases (ranking 1 to 5 ) and 5 worst cases (ranking 131 to 135).

\begin{tabular}{|c|c|c|c|c|c|c|c|c|c|}
\hline \multirow{2}{*}{ Case, $i$} & \multirow{2}{*}{$\begin{array}{l}\text { Collector } \\
\text { type }\end{array}$} & \multirow{2}{*}{$\begin{array}{l}\text { Air mass flow rate } m, \mathrm{~kg} / \\
\mathrm{s}\end{array}$} & \multirow{2}{*}{$\begin{array}{c}\text { Collector length } L, \\
\mathrm{~m}\end{array}$} & \multirow{2}{*}{$\begin{array}{c}\text { Channel depth } H, \\
\text { m }\end{array}$} & \multicolumn{3}{|c|}{ Objectives } & \multirow{2}{*}{$\Omega$} & \multirow{2}{*}{ Ranking } \\
\hline & & & & & $\eta_{\mathrm{Eff}}$ & $N_{\text {plate }}$ & $\eta_{\mathrm{II}}$ & & \\
\hline 7 & 1 & 0.01 & 2.5 & 0.02 & 0.5209 & 4 & 0.04733 & 0.8493 & 1 \\
\hline 61 & 3 & 0.01 & 2.5 & 0.02 & 0.4629 & 3 & 0.03864 & 0.8423 & 2 \\
\hline 70 & 3 & 0.015 & 2.5 & 0.02 & 0.5344 & 3 & 0.03273 & 0.8379 & 3 \\
\hline 8 & 1 & 0.01 & 2.5 & 0.025 & 0.509 & 4 & 0.04626 & 0.8357 & 4 \\
\hline 4 & 1 & 0.01 & 2 & 0.02 & 0.5504 & 4 & 0.04266 & 0.8319 & 5 \\
\hline 120 & 5 & 0.015 & 1.5 & 0.03 & 0.4412 & 3 & 0.01501 & 0.6662 & 131 \\
\hline 100 & 4 & 0.02 & 1.5 & 0.02 & 0.6125 & 4 & 0.01302 & 0.6571 & 132 \\
\hline 114 & 5 & 0.01 & 2 & 0.03 & 0.356 & 3 & 0.01942 & 0.6531 & 133 \\
\hline 111 & 5 & 0.01 & 1.5 & 0.03 & 0.3694 & 3 & 0.01589 & 0.6354 & 134 \\
\hline 19 & 1 & 0.02 & 1.5 & 0.02 & 0.6513 & 4 & 0.005287 & 0.6231 & 135 \\
\hline
\end{tabular}

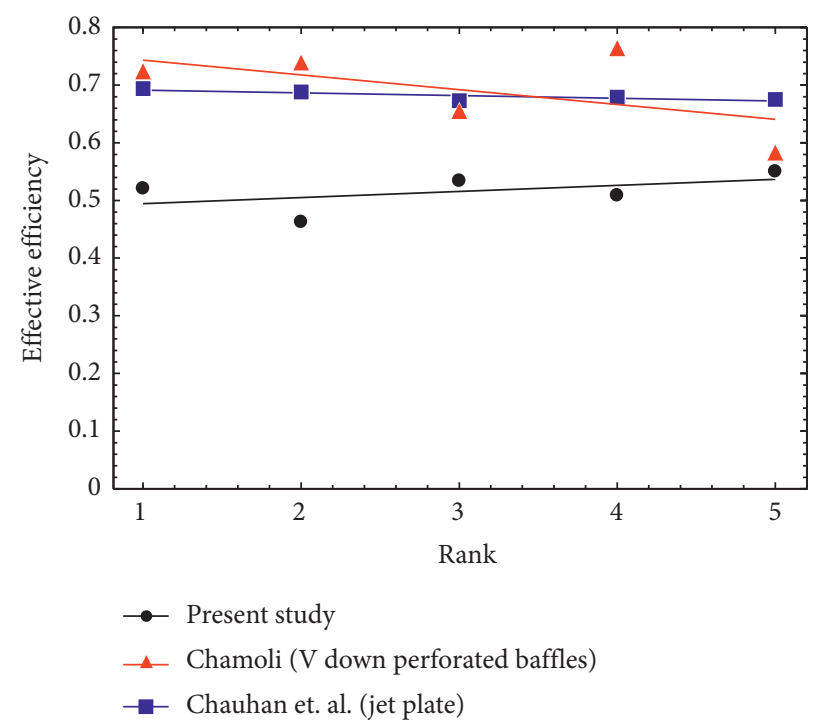

Figure 10: Comparison of five best cases of the present flat plate, jet plate [41], and V down perforated baffles on absorber plate [40].

three of five worst cases (cases 120,114, and 111). From the PSI method, it can be concluded that types 1 and 3 with suitable geometry and operating parameters are the two SAHs that should be selected in multipass air collector configurations.

Figure 10 shows a comparison of optimal results from the PSI method for the objective function of effective efficiency. Two configurations compared to the current study were single-pass SAHs with impinging air jet plate [41] and $\mathrm{V}$ down perforated baffles on absorber plate [40]. It can be seen that the effective efficiency of flat-plate air collector in the present study is lower than that of collectors with special modification and insertion. This results in low convection heat transfer coefficient of a smooth duct compared to others. However, with the change of flow configuration to types 1 (triple pass) or 3 (double pass), the flat-plate air collector can compete with other types. Especially at rank 5, the effective efficiency of triple-pass $\mathrm{SAH}$ is approximately equal to single-pass $\mathrm{SAH}$ with the roughness of $\mathrm{V}$ down perforated baffles.

\section{Conclusions}

The various configurations of the multipass flat-plate air collector have been analysed in this paper. The configurations include the number of passes from 1 to 3 , and the number of glass covers is 1 or 2 with/without back plate. Independent parameters comprise collector length, air channel depth, and air mass flow rate to examine the efficiencies. Multiobjective optimization of the maximum 
effective, exergy efficiencies, and minimum number of plates, i.e., glass cover, absorber plate, and back plate, were conducted using the preference selection index method. The main results are drawn as follows:

(i) Triple-pass SAH has the highest effective efficiency followed by double-pass type and single-pass type. The efficiency of the triple-pass type is $30 \%$ higher than that of single-pass type. Among the doublepass types, type 4 obtained the largest effective efficiency.

(ii) Exergy performance is maximum when the air flow rate is between 0.005 and $0.01 \mathrm{~kg} / \mathrm{s}$.

(iii) The triple-pass type has the highest exergy performance that is twice as high as the single-pass type. Type 4 also yielded the biggest effective efficiency among the double-pass SAHs.

(iv) Effective efficiency decreases when increasing the collector length. In contrast, exergy performance increases with the length.

(v) As the collector depth increases, the effective efficiency decreases. The exergy performance of the triple-pass type is maximum at the collector depth of $19 \mathrm{~mm}$. For other types, the exergy performance decreases when increasing the collector depth.

Adopting the multiobjective optimization, it is obviously confirmed that the triple-pass solar air heater is the best arrangement at low flow rate and the worst case at high flow rate. This is because at low flow rate, the effective efficiency and exergy efficiency of triple-pass type are quite large compared to other types. But at high flow rate, the exergy performance is too poor with a considerable investment cost.

\section{Appendix}

\section{A. Thermal Transport Modelling for Solar Air Heater Types 2 to 5}

A.1. Type 2. Glass cover

$$
\begin{aligned}
\alpha_{g} I= & h_{w}\left(T_{g}-T_{a}\right)+h_{r, g, s}\left(T_{g}-T_{s}\right) \\
& +h_{c, g, f 1}\left(T_{g}-T_{f 1}\right)+h_{r, g, p}\left(T_{g}-T_{p}\right) .
\end{aligned}
$$

Air in $1^{\text {st }}$ pass

$$
\begin{aligned}
Q_{1}= & m c_{p}\left(T_{f 1, o}-T_{a}\right)=L b h_{c, g, f 1}\left(T_{g}-T_{f 1}\right) \\
& +L b h_{c, p, f 1}\left(T_{p}-T_{f 1}\right) .
\end{aligned}
$$

Absorber plate

$$
\begin{aligned}
\alpha_{g} \tau_{g} I= & h_{c, p, f 1}\left(T_{p}-T_{f 1}\right)+h_{r, p, g}\left(T_{p}-T_{g}\right) \\
& +h_{c, p, f 2}\left(T_{p}-T_{f 2}\right)+h_{r, p, b}\left(T_{p}-T_{b}\right) .
\end{aligned}
$$

Air in $2^{\text {nd }}$ pass

$$
\begin{aligned}
Q_{2}= & m c_{p}\left(T_{f 2, o}-T_{f 1, o}\right)=L b h_{c, p, f 2}\left(T_{p}-T_{f 2}\right) \\
& +L b h_{c, b, f 2}\left(T_{b}-T_{f 2}\right) .
\end{aligned}
$$

Back plate

$$
h_{r, p, b}\left(T_{p}-T_{b}\right)=h_{c, b, f 2}\left(T_{b}-T_{f 2}\right)+h_{b}\left(T_{b}-T_{a}\right) \text {. }
$$

A.2. Type 3. Upper glass cover

$$
\begin{aligned}
\alpha_{g} I= & h_{w}\left(T_{g 1}-T_{a}\right)+h_{r, g 1, s}\left(T_{g 1}-T_{s}\right) \\
& +h_{c, g 1, f 1}\left(T_{g 1}-T_{f 1}\right)+h_{r, g 1, g 2}\left(T_{g 1}-T_{g 2}\right) .
\end{aligned}
$$

Air in $1^{\text {st }}$ pass

$$
\begin{aligned}
Q_{1}= & m c_{p}\left(T_{f 1, o}-T_{a}\right)=L b h_{c, g 1, f 1}\left(T_{g 1}-T_{f 1}\right) \\
& +L b h_{c, g 2, f 1}\left(T_{g 2}-T_{f 1}\right) .
\end{aligned}
$$

Lower glass cover

$$
\begin{aligned}
\alpha_{g} \tau_{g} I= & h_{c, g 2, f 1}\left(T_{g 2}-T_{f 1}\right)+h_{r, g 1, g 2}\left(T_{g 2}-T_{g 1}\right) \\
& +h_{c, f 2, g 2}\left(T_{g 2}-T_{f 2}\right)+h_{r, g 2, p}\left(T_{g 2}-T_{p}\right) .
\end{aligned}
$$

Air in $2^{\text {nd }}$ pass

$$
\begin{aligned}
\alpha_{p} \tau_{g}^{2} I= & h_{c, p, f 2}\left(T_{p}-T_{f 2}\right)+h_{r, g 2, p}\left(T_{p}-T_{g 2}\right) \\
& +h_{b}\left(T_{p}-T_{a}\right) .
\end{aligned}
$$

A.3. Type 4. Upper glass cover

$$
\begin{aligned}
\alpha_{g} I= & h_{w}\left(T_{g 1}-T_{a}\right)+h_{r, g 1, s}\left(T_{g 1}-T_{s}\right) \\
& +\left(h_{c, g 1, g 2}+h_{r, g 1, g 2}\right)\left(T_{g 1}-T_{g 2}\right) .
\end{aligned}
$$

Lower glass cover

$$
\begin{aligned}
\alpha_{g} \tau_{g} I= & \left(h_{c, g 1, g 2}+h_{r, g 1, g 2}\right)\left(T_{g 2}-T_{g 1}\right) \\
& +h_{r, g 2, p}\left(T_{g 2}-T_{p}\right)+h_{c, g 2, f}\left(T_{g 2}-T_{f 1}\right) .
\end{aligned}
$$

Air in $1^{\text {st }}$ pass

$$
\begin{aligned}
Q_{1}= & m c_{p}\left(T_{f 1, o}-T_{a}\right)=L b h_{c, g 2, f 1}\left(T_{g 2}-T_{f 1}\right) \\
& +L b h_{c, p, f 1}\left(T_{p}-T_{f 1}\right) .
\end{aligned}
$$


Absorber plate

$$
\begin{aligned}
\alpha_{p} \tau_{g}^{2} I= & h_{c, p, f 1}\left(T_{p}-T_{f 1}\right)+h_{r, g 2, p}\left(T_{p}-T_{g 2}\right) \\
& +h_{c, p, f 2}\left(T_{p}-T_{f 2}\right)+h_{r, p, b}\left(T_{p}-T_{b}\right) .
\end{aligned}
$$

Air in $2^{\text {nd }}$ pass

$$
\begin{aligned}
Q_{2}= & m c_{p}\left(T_{f 2, o}-T_{f 1, o}\right)=L b h_{c, p, f 2}\left(T_{p}-T_{f 2}\right) \\
& +L b h_{c, b, f 2}\left(T_{b}-T_{f 2}\right) .
\end{aligned}
$$

Back plate

$$
h_{r, p, b}\left(T_{p}-T_{b}\right)=h_{c, b, f 2}\left(T_{b}-T_{f 2}\right)+h_{b}\left(T_{b}-T_{a}\right) \text {. }
$$

\section{A.4. Type 5. Upper glass cover}

$$
\begin{aligned}
\alpha_{g} I= & h_{w}\left(T_{g 1}-T_{a}\right)+h_{r, g 1, s}\left(T_{g 1}-T_{s}\right) \\
& +\left(h_{c, g 1, g 2}+h_{r, g 1, g 2}\right)\left(T_{g 1}-T_{g 2}\right) .
\end{aligned}
$$

Lower glass cover

$$
\begin{aligned}
\alpha_{g} \tau_{g} I= & \left(h_{c, g 1, g 2}+h_{r, g 1, g 2}\right)\left(T_{g 2}-T_{g 1}\right) \\
& +h_{r, g 2, p}\left(T_{g 2}-T_{p}\right)+h_{c, g 2, f}\left(T_{g 2}-T_{f}\right) .
\end{aligned}
$$

Air

$$
\begin{aligned}
Q= & m c_{p}\left(T_{o}-T_{a}\right)=L b h_{c, g 2, f}\left(T_{g 2}-T_{f}\right) \\
& +L b h_{c, p, f}\left(T_{p}-T_{f}\right) .
\end{aligned}
$$

Absorber plate

$$
\alpha_{p} \tau_{g}^{2} I=h_{c, p, f}\left(T_{p}-T_{f}\right)+h_{r, g 2, p}\left(T_{p}-T_{g 2}\right)+h_{b}\left(T_{p}-T_{a}\right)
$$

\section{Nomenclature}

$A_{c}: \quad$ Area of the absorber plate $\left(\mathrm{m}^{2}\right)$

$b$ : $\quad$ Collector width (m)

$c_{p}$ : Specific heat at a constant pressure $(\mathrm{J} / \mathrm{kg}-\mathrm{K})$

$D_{h}: \quad$ Hydraulic diameter $(\mathrm{m})$

EX: Exergy (W)

$f: \quad$ Friction factor

$h$ : $\quad$ Heat transfer coefficient $\left(\mathrm{W} / \mathrm{m}^{2}-\mathrm{K}\right)$

$H$ : Channel depth $(\mathrm{m})$

I: $\quad$ Solar radiation $\left(\mathrm{W} / \mathrm{m}^{2}\right)$

$k$ : Thermal conductivity $(\mathrm{W} / \mathrm{m}-\mathrm{K})$

$L: \quad$ Collector length (m)

$m$ : Air mass flow rate $(\mathrm{kg} / \mathrm{s})$

$n_{\text {glass: }}$ Number of glasses

$n_{\text {pass: }}$ Number of passes

$N_{\text {plate }}$ Total number of plates (absorber plate, back plate, glass cover)

P: $\quad$ Pressure $(\mathrm{Pa})$

Pr: $\quad$ Prandtl number

Q: $\quad$ Heat transfer rate $(\mathrm{W})$

Re: Reynolds number
T: $\quad$ Temperature $(\mathrm{K})$

$t: \quad$ Thickness (m)

$U_{L}: \quad$ Overall heat loss coefficient $\left(\mathrm{W} / \mathrm{m}^{2}-\mathrm{K}\right)$

$U_{t}: \quad$ Top loss coefficient $\left(\mathrm{W} / \mathrm{m}^{2}-\mathrm{K}\right)$

$V: \quad$ Velocity $(\mathrm{m} / \mathrm{s})$

Greek symbols

$\alpha$ : Absorptivity

$\rho:$ Air density $\left(\mathrm{kg} / \mathrm{m}^{3}\right)$

$\Delta$ : Difference

$\mu$ : Dynamic viscosity (Pa.s)

$\eta$ : Efficiency

$\varepsilon:$ Emissivity

$\Omega$ : Preference selection index

$\sigma$ : Stefan constant

$\tau$ : Transmissivity

Subscripts

a: Ambient

$b$ : Back plate

c: Convection

Eff: Effective

$f: \quad$ Fluid (air)

$g$ : Glass cover

I: First law

$i$ : Insulation

II: Second law

$o$ : Outlet

p: Absorber plate

$r$ : Radiation

s: $\quad$ Sky

$w$ : Wind.

\section{Data Availability}

No data were used to support this study.

\section{Conflicts of Interest}

The authors declare that they have no conflicts of interest.

\section{Acknowledgments}

This research is funded by the Vietnam National University Ho Chi Minh City (VNU-HCM) under grant number B2021-20-06.

\section{References}

[1] K. A. Joudi and A. A. Farhan, "Greenhouse heating by solar air heaters on the roof," Renewable Energy, vol. 72, pp. 406-414, 2014.

[2] S. Pramuang and R. H. B. Exell, "The regeneration of silica gel desiccant by air from a solar heater with a compound parabolic concentrator," Renewable Energy, vol. 32, no. 1, pp. 173-182, 2007.

[3] T. Koyuncu, "Performance of various design of solar air heaters for crop drying applications," Renewable Energy, vol. 31, no. 7, pp. 1073-1088, 2006.

[4] N. Minh Phu and N. Thanh Luan, "A review of energy and exergy analyses of a roughened solar air heater," Journal of 
Advanced Research in Fluid Mechanics and Thermal Sciences, vol. 77, no. 2, pp. 160-175, 2020.

[5] N. M. Phu, T. T. Bao, H. N. Hung, N. T. Tu, and N. Van Hap, "Analytical predictions of exergoeconomic performance of a solar air heater with surface roughness of metal waste," Journal of Thermal Analysis and Calorimetry, 2020.

[6] N. T. Luan and N. M. Phu, "Thermohydraulic correlations and exergy analysis of a solar air heater duct with inclined baffles," Case Studies in Thermal Engineering, vol. 21, Article ID 100672, 2020.

[7] N. M. Phu and N. Van Hap, "Performance evaluation of a solar air heater roughened with conic-curve profile ribs based on efficiencies and entropy generation," Arabian Journal for Science and Engineering, vol. 45, no. 11, pp. 9023-9035, 2020.

[8] R. Chandra, N. P. Singh, and M. S. Sodha, "Thermal performance of a triple-pass solar air collector," Energy Conversion and Management, vol. 30, no. 1, pp. 41-48, 1990.

[9] C. Choudhury, P. M. Chauhan, H. P. Garg, and S. N. Garg, "Cost-benefit ratio of triple pass solar air heaters," Energy Conversion and Management, vol. 37, no. 1, pp. 95-116, 1996.

[10] F. K. Forson, M. A. A. Nazha, and H. Rajakaruna, "Experimental and simulation studies on a single pass, double duct solar air heater," Energy Conversion and Management, vol. 44, no. 8, pp. 1209-1227, 2003.

[11] M. R. I. Ramadan, A. A. El-Sebaii, S. Aboul-Enein, and E. El-Bialy, "Thermal performance of a packed bed double-pass solar air heater," Energy, vol. 32, no. 8, pp. 1524-1535, 2007.

[12] K. Sopian, M. A. Alghoul, E. M. Alfegi, M. Y. Sulaiman, and E. A. Musa, "Evaluation of thermal efficiency of double-pass solar collector with porous-nonporous media," Renewable Energy, vol. 34, no. 3, pp. 640-645, 2009.

[13] B. M. Ramani, A. Gupta, and R. Kumar, "Performance of a double pass solar air collector," Solar Energy, vol. 84, no. 11, pp. 1929-1937, 2010.

[14] A. A. El-Sebaii, S. Aboul-Enein, M. R. I. Ramadan, S. M. Shalaby, and B. M. Moharram, "Investigation of thermal performance of-double pass-flat and v-corrugated plate solar air heaters," Energy, vol. 36, no. 2, pp. 1076-1086, 2011.

[15] A. A. El-Sebaii, S. Aboul-Enein, M. R. I. Ramadan, S. M. Shalaby, and B. M. Moharram, "Thermal performance investigation of double pass-finned plate solar air heater," Applied Energy, vol. 88, no. 5, pp. 1727-1739, 2011.

[16] C.-D. Ho, C.-S. Lin, Y.-C. Chuang, and C.-C. Chao, "Performance improvement of wire mesh packed double-pass solar air heaters with external recycle," Renewable Energy, vol. 57, pp. 479-489, 2013.

[17] Ho-M. Yeh, "Effect of pass number on collector efficiency in downward-type multipass solar air heaters," Journal of Applied Science and Engineering, vol. 17, no. 2, 2014.

[18] P. Velmurugan and R. Kalaivanan, "Energy and exergy analysis of multi-pass flat plate solar air heater-an analytical approach," International Journal of Green Energy, vol. 12, no. 8, pp. 810-820, 2014.

[19] P. Velmurugan and R. Kalaivanan, "Thermal performance studies on multi-pass flat-plate solar air heater with longitudinal fins: an analytical approach," Arabian Journal for Science and Engineering, vol. 40, no. 4, pp. 1141-1150, 2015.

[20] P. Velmurugan and R. Kalaivanan, "Energy and exergy analysis of solar air heaters with varied geometries," Arabian Journal for Science and Engineering, vol. 40, no. 4, pp. 11731186, 2015.

[21] P. Velmurugan and R. Kalaivanan, "Energy and exergy analysis in double-pass solar air heater," Sadhana, vol. 41, no. 3, 2016.
[22] A. K. Raj, G. Kunal, M. Srinivas, and S. Jayaraj, "Performance analysis of a double-pass solar air heater system with asymmetric channel flow passages," Journal of Thermal Analysis and Calorimetry, vol. 136, no. 1, pp. 21-38, 2018.

[23] S. Abo-Elfadl, M. S. Yousef, and H. Hassan, "Assessment of double-pass pin finned solar air heater at different air mass ratios via energy, exergy, economic, and environmental (4E) approaches," Environmental Science and Pollution Research, vol. $28,2020$.

[24] H. Hassan and S. Abo-Elfadl, "Experimental study on the performance of double pass and two inlet ports solar air heater (SAH) at different configurations of the absorber plate," Renewable Energy, vol. 116, pp. 728-740, 2018.

[25] D. K. Rabha, D. Pathak, R. Baruah, T. Kalita, and A. Sharma, "Experimental investigation of the performance of a doublepass unglazed transpired solar air heater," in Lecture Notes in Mechanical Engineering, pp. 571-584, Springer, Singapore, 2019.

[26] S. Abo-Elfadl, H. Hassan, and M. F. El-Dosoky, "Study of the performance of double pass solar air heater of a new designed absorber: an experimental work," Solar Energy, vol. 198, pp. 479-489, 2020.

[27] A. I. N. Korti, "Numerical 3-D heat flow simulations on double-pass solar collector with and without porous media," Journal of Thermal Engineering, vol. 1, no. 1, p. 10, 2015.

[28] E. M. S. El-Said, "Numerical investigations of fluid flow and heat transfer characteristics in solar air collector with curved perforated baffles," Engineering Reports, vol. 2, no. 4, 2020.

[29] A. Khanlari, A. Sözen, F. Afshari, C. Şirin, A. D. Tuncer, and A. Gungor, "Drying municipal sewage sludge with v-groove triple-pass and quadruple-pass solar air heaters along with testing of a solar absorber drying chamber," Science of The Total Environment, vol. 709, Article ID 136198, 2020.

[30] A. D. Tuncer, A. Sözen, A. Khanlari, A. Amini, and C. Şirin, "Thermal performance analysis of a quadruple-pass solar air collector assisted pilot-scale greenhouse dryer," Solar Energy, vol. 203, pp. 304-316, 2020.

[31] S. Singh, "Experimental and numerical investigations of a single and double pass porous serpentine wavy wiremesh packed bed solar air heater," Renewable Energy, vol. 145, pp. 1361-1387, 2020.

[32] A. Heydari, M. Mesgarpour, and S. Wongwises, "Geometry optimization of double pass solar air heater with helical flow path," Solar Energy, vol. 213, pp. 67-80, 2021.

[33] S. Kesavan, T. V. Arjunan, and S. Vijayan, "Thermodynamic analysis of a triple-pass solar dryer for drying potato slices," Journal of Thermal Analysis and Calorimetry, vol. 136, no. 1, pp. 159-171, 2018.

[34] P. Sudhakar and M. Cheralathan, "Thermal performance enhancement of solar air collector using a novel V-groove absorber plate with pin-fins for drying agricultural products: an experimental study," Journal of Thermal Analysis and Calorimetry, vol. 140, no. 5, pp. 2397-2408, 2019.

[35] M. M. Hegazy, A. El-Sebaii, M. R. Ramadan, S. Aboul-Enein, and A. E.-M. Khallaf, "Comparative study of three different designs of a hybrid PV/T double-pass finned plate solar air heater," Environmental Science and Pollution Research, vol. 27, no. 26, pp. 32270-32282, 2020.

[36] W. H. McAdams, Heat Transmission, McGraw-Hill, New York, NY, USA, 3rd edition, 1954.

[37] F. W. Dittus and L. M. K. Boelter, Heat Transfer in Automobile Radiators of the Tubular Type, University of California Publications on Engineering, 1930. 
[38] M. M. Matheswaran, T. V. Arjunan, and D. Somasundaram, "Analytical investigation of solar air heater with jet impingement using energy and exergy analysis," Solar Energy, vol. 161 , pp. 25-37, 2018.

[39] J. A. Duffie and W. A. Beckman, Solar Engineering of Thermal Processes, John Wiley \& Sons, Hoboken, NY, USA, 4th edition, 2013.

[40] S. Chamoli, "Preference selection index approach for optimization of $\mathrm{V}$ down perforated baffled roughened rectangular channel," Energy, vol. 93, pp. 1418-1425, 2015.

[41] R. Chauhan, T. Singh, N. S. Thakur, and A. Patnaik, "Optimization of parameters in solar thermal collector provided with impinging air jets based upon preference selection index method," Renewable Energy, vol. 99, pp. 118-126, 2016.

[42] K. Maniya and M. G. Bhatt, "A selection of material using a novel type decision-making method: preference selection index method," Materials \& Design, vol. 31, no. 4, pp. 1785-1789, 2010.

[43] S. Mufazzal and S. M. Muzakkir, "Identification of optimal alternative as a prospective candidate for further design improvements using preference selection index method," in Proceedings of the 2017 International Conference on Innovations in Control, Communication and Information Systems (ICICCI), Bangkok, Thailand, August 2017. 